\title{
Simultaneus Primary Submersible Tolstokishechnj Anastomosis
}

\author{
Shaposhnikov Veniamin Ivanovich* \\ Noncommercial educational private institution of higher education Kuban Medical Institute, Russia
}

*Corresponding author: Shaposhnikov Veniamin Ivanovich, Noncommercial educational private institution of higher education, Russia

\begin{tabular}{|c|c|}
\hline ARTICLE INFO & ABSTRACT \\
\hline Received: 蔧January 28, 2019 & Colon cancer, which occurs without acute obturative intestinal obstruction, the author \\
\hline Published: 豐 February 11, 2019 & $\begin{array}{l}\text { proposes to impose primary tolstokishechnyj anastomosis. It reduces the risk of postop- } \\
\text { erative peritonitis. This is achieved by dipping the anastomosis for }-3.53 .0 \mathrm{~cm} \text { clearance }\end{array}$ \\
\hline $\begin{array}{l}\text { Citation: Shaposhnikov Veniamin } \\
\text { Ivanovich. Simultaneus Prima- }\end{array}$ & $\begin{array}{l}\text { in the distal colon. The technique was applied at } 3 \text { patients. Colon cancer was discovered } \\
\text { accidentally during an operation carried out at the acute cholecystitis. All patients carried } \\
\text { out simultaneous operations. Com-plications were observed. }\end{array}$ \\
\hline
\end{tabular}

ry Submersible Tolstokishech-

nj Anastomosis. Biomed J Sci

\& Tech Res 14(3)-2019. BJSTR.

MS.ID.002545.

\section{Introduction}

Colon cancer refers to the leading oncological problems. He is $4-6 \%$ of all malignant tumors in humans (8-9). Most often it occurs in the age of 40-60 years and mostly in men (3:2). In the year 2015 at 100000 of the population accounted for observing this cancer 132.9 localization, and in 2017 year 142.9, i.e. notable growth of the disease (3.4). Of the number of patients with newly diagnosed stage I-II process has been installed at $47.2 \%$, which allows you to perform a primary resection of the colon or the public, or (private) laparoscopic ally [1-4]. However, as a rule, patients arrive with the phenomena of acute obturative intestinal obstruction, which have made it difficult to provide them with medical assistance [5]. This happens because of the sharp increase in the volume of colon fragment lying above the tumor and its overflow gases, liquid and dense kalovymi masses. Manipulating the gut becomes dangerous because of the threat of getting this content in the free abdominal cavity that leads to the development of putrid peritonitis. Makes it difficult to overlay the primary anastomosis and intestine width difference above and below the for all these reasons and more, running or left-hand or right-sided gemikoljektomija. If the right half colon cancer manages to preserve the natural passage of fecal masses (ileotransverzoanastomoza blend), cancer of the left half of the already have a colostomy impose and further carry out reconstructive surgery tumor [6].
Post-operative life expectancy in these patients depends on the local distribution of cancer process and the availability of regional and distant metastases [7-10]. On the outcome of the operation impact and prevention methods of peritonitis. 2017 year in this disease only surgical treatment in Russia was applied at $68.1 \%$ of patients, and combined or integrated-from 31.9\% (3.4). For staging of tumorous process and identify clinical prediction, widespread dissemination and recognition of international classification of colorectal cancer, the proposed International Anti-cancer Union using characters of the TNM (Tumor, Metastases, Nodules). The most frequent and constant symptom of colon cancer are different types of bowel function disorders, which usually lead to acute intestinal obstruction. Pain sensations appear when local spread of the tumor, especially when moving it to surrounding organs and tissues. Violation of the general condition of patients (weakness, fatigue, anemia, weight loss, pallor of the skin) due to hidden blood losses daily, as well as neoplastic intoxication and observed in the later stages of the disease.

Sometimes going $\mathrm{c}$ intestinal bleeding that requires urgent surgical treatment. The doctor has pretty great opportunities for timely diagnosis of colon cancer in its early stages. We just have to have cancer suspicion. For this purpose, use: colonoscopy, occult blood feces analysis, cytology rinsate, computed tomography, 
laparoscopy, etc. The main radical operations without the phenomena of acute intestinal obstruction include:

a) Primary resection of colon by open or laparoscopic manner

b) Resection of the left or right half of the colon without restoring its continuity on the method Hartmann. The palliative interventions include same colostomy and ileostomy (trailer, loop, double barreled) and bypass anastomosis. Choice of surgery for cancer of the colon is very complicated and depends on many factors: severity of acute intestinal obstruction, tumor, macro-and microscopic its structure, the degree of local spread of tumors process, its metastasis and general condition of the patient, as well as a possible follow-up social and lab our rehabilitation of these patients. These tumors are relatively rare in other operations are identified by chance when pimiento is performed an audit of the abdominal organs, and before that they leaked asymptomatic. These observations are of particular value because they emphasize the importance of preventive examinations in the population with a view to identifying covertly leaking tumors.

\section{Material and Methods}

The 815 cholecystectomy performed in person at various hospitals in Krasnodar (Russia), 3 (0.38\%) audit observations the abdominal organs were accidentally revealed malignant tumors of the large intestine. All of the patients were men aged 55 to 62 years. All of them have the tumor was in the area of selezjonochnogo her angle. In such a situation requiring simultaneous operation is subject to the fulfillment of the primary resection of the affected intestine with submersible anastomosis. The goal was achieved as follows. After gallbladder removal on one of the most common techniques to produce expansion of wounds in epigastralna area in transverse direction and began to mobilize the affected colon by ordinary methods. The absence of faecal masses in the bowel lumen, allowing perform a primary resection of the authority. Following this single-row stitch podslizistomyshechnyj overlaid knots inside. Otpreparovyvalas followed in the distal peritoneum direction from the anastomosis (for up to $3 \mathrm{~cm}$.) this was relatively easy, since it is not podshivalas when creating the anastomosis. On otsloennuju seroznuju wrapped around the entire perimeter of the superimposed clip 4-5 (for tensioning and retain these tissues taut.) around the perimeter of the gut produce dive anastomosis under otsloennuju the peritoneum. Then, in the taut, otsloennuju individual nodes, peritoneum podshivali seams to the perito-neum and proximal end. Thus, the anastomosis has been completely submerged in the lumen of the colon, and if insolvency was its seams, this does not lead to the development of peritonitis. At the end of the manipulation in the rectum injected vapor tube.

The result of all these patients safely recovering from an operation in the colon and gall bladder. Duration of hospitalization accounted for 14-15 days. Form tumor histology is adenocarcinoma. The length of the gut wall tumor lesions was from 4 to $6 \mathrm{~cm}$ and it is not prorastala her wall, leaving free to half its diameter. During an operation found that the tumor is movable, IE not grows into surrounding tissues. All these data necessary for simultaneous production just did an operation because it could immediately correct both pathological process-and in the area of the gall bladder and the colon.

\section{Discussion}

In the presence of acute colonic obstruction, combine holecistjektomiju or other operation, with primary colon resection is not recommended, as this may lead to the development of putrid peritonitis. This is due to the fact that shovnuju thread will inevitably have to navigate through fecal masses. These observations after removal of tumors impose or single-colostomy (on both ends of the colon), or produce gemikoljektomii and via 3-4 month carry out reconstructive surgery. In those same three observations were favorable conditions for primary colon resection. Without going into the details of group operations, you must specify that they should be held more frequently, and for this it is necessary to detect colon tumors prior to development in patients this complication. So, for example, of the 315 patients admitted to the hospital with symptoms of acute colonic obstruction, 14 (4.4\%) earlier during the period from 3 up to 6 months in various hospitals were subjected to laparoscopic cholecystectomy. There can be no doubt that the tumor they have during the operation already had, but a proper audit of abdominal cavity then did not, and she has not been diagnosed. Simultaneous operations that were performed in these 3 patients got rid of severe discomfort associated with a colostomy, the repeated reconstructive surgery and hospitalization time is halved, i.e. have an explicit social and economic effect.

\section{Conclusion}

The primary submersible tolstokishechnyj anastomosis helps reduce the risk of postoperative peritonitis, as he plunges into a wall off the Division, even if insolvency comes seams, this will not lead to infection abdominal cavity. Clinical observations fully confirm this conclusion. When implementing the laparoscopic operations necessary to produce a thorough audit of the abdomen to detect colon tumors and other tissue in the early stages of their development.sss

\section{References}

1. Denisenko VL, Gain YM, Shakhrai SV (2012) Problems and prospects of surgical treatment of acute complications of colorectal cancer. Bulletin of the National medico-surgical Center. N I Pirogov M 1: 36-43.

2. Drobni S h (1983) Bowel Surgery. Budapest

3. Kaprin AD, Starinskij VV, Petrov GV (2016) State of Oncology aid rendered to population of Russia in the year 2015 (morbidity and mortality) 1: 18-31.

4. Kaprin AD, Starinskij VV, Petrov GV (2018) State of Oncology aid rendered to population of Russia in the year 2017 (morbidity and mortality) 1: 18-31.

5. Maurice E, Aregvi, Jonathan M, Sakiera A (1999) Miniinvasive Coloproctology. medicine p. 64.

6. Fedorov VD, Sparrows, V l Rivkin GI (1994) Clinical operational Coloproctology. medicine pp. 335. 
7. Phillips Robyn CS (2009) Translated from Arabic GI Voroboews. Colorectal Surgery. geotar-media 3: 306.

8. Hanevich MD (2008) Colorectal cancer. Selection of surgical treatment for colonic obstruction. SPb Agraffe 1: 136.

\section{ISSN: 2574-1241}

DOI: 10.26717.BJSTR.2019.14.002545

Shaposhnikov Veniamin Ivanovich. Biomed J Sci \& Tech Res

(C) This work is licensed under Creative

Submission Link: https://biomedres.us/submit-manuscript.php
9. Yaik NA, Sedov VM, Vasilyev SV (2004) Tumors of the colon. M Med press inform 2: 153-206.

10. Jacobs M, Verdeja JC Goldstein HS (1991) USV Minimally colon resection (laparoscopic colecto-my). Surgical laparoscopy \& endoscopy 1(3): 144150 .

$\begin{array}{ll}\text { BIOMEDICAL } & \text { Assets of Publishing with us } \\ \text { RESEARCHES } & \text { - Global archiving of articles } \\ & \text { - Immediate, unrestricted online access } \\ & \text { - Rigorous Peer Review Process } \\ \end{array}$

